\title{
Antioxidant and ACE Inhibiting Activities of the Rockfish Sebastes hubbsi Skin Gelatin Hydrolysates Produced by Sequential Two-step Enzymatic Hydrolysis
}

\author{
Hyung Jun Kim¹, Kwon Hyun Park², Jun Ho Shin², Ji Sun Lee, \\ Min Soo Heu ${ }^{3}$, Dong Ho Lee ${ }^{1}$ and Jin-Soo Kim ${ }^{2 *}$ \\ ${ }^{1}$ Children's Dietary Life Safety Division, Korea Food \& Drug Administration, \\ Cheongwon 363-951, Korea \\ ${ }^{2}$ Department of Seafood Science and Technology/Institute of Marine Industry, \\ Gyeongsang National University, Tongyeong 650-160, Korea \\ ${ }^{3}$ Department of Food Science and Nutrition/Institute of Marine Industry, \\ Gyeongsang National University, Jinju 660-701, Korea
}

\begin{abstract}
This study was conducted to obtain hydrolysates with potent antioxidative activity from rockfish skin gelatin. Gelatin was extracted under high temperature/high pressure using a two-step enzymatic hydrolysis with commercial enzymes such as Alcalase, Flavourzyme, Neutrase, and Protamex. The second rockfish-skin gelatin hydrolysate (SRSGH) was prepared by further incubating the first gelatin hydrolysate (FRSGH), which had been hydrolyzed with Alcalase for $1 \mathrm{~h}$ (FRSGH-A1), with Flavourzyme for $2 \mathrm{~h}$ (SRSGH-F2). The second gelatin hydrolysate showed higher antioxidative activity of 3.72 as measured by a Metrohm Rancimat and superior angiotensin I-converting enzyme (ACE) inhibiting activity of $0.82 \mathrm{mg} / \mathrm{mL}$. Compared with the gelatin, the relative proportion in SRSGH-F2 was markedly decreased in the $100 \mathrm{kDa}$ peak, whereas it was increased in that less than $100-\mathrm{kDa}$. The amino acid composition of SRSGH-F2 was rich in glycine $(25.9 \%)$, proline $(10.8 \%)$, alanine $(9.1 \%)$, and glutamic acid $(9.1 \%)$. In contrast, it was poor in cystine (not detected), methionine (1.6\%), tyrosine $(0.4 \%)$, hydroxylysine $(0.9 \%)$, and histidine $(0.9 \%)$. In recent years, demand for natural functional foods has been increasing, and SRSGH-F2 can be used as a functional food ingredient in the food industries. However, further detailed studies on SRSGH-F2 with regard to its antioxidant activity in vivo and the various antioxidant mechanisms are needed.
\end{abstract}

Key words: Rockfish skin, Fish skin, Gelatin, Fish skin gelatin, Gelatin hydrolysate

\section{Introduction}

Rockfish is one of the top aquaculture products in Korea, with an estimated yield of 3,178 M/T in 2009 (Fishery Production Survey, 2010). These large yields provide a unique opportunity for gelatin extraction from rockfish skin, which is generated in sizeable quantities (approximately $3.4 \%$ based on whole fish) as a by-product from sliced raw fish production. However, the use of rockfish skin in human foodstuff production has not been widely studied to date. Because of the low rheological properties of fish gelatin compared with land-animal gelatins (Kim and

\footnotetext{
*Corresponding author: jinsukim@gnu.ac.kr
}

Park, 2004), most rockfish skin is usually used to produce fish meals and fertilizers or is directly discharged into rivers and estuaries, resulting in environmental pollution (Kim et al., 2009). However, both fish gelatin and land-animal gelatin can be converted into biologically active peptides by enzymatic hydrolysis, and the resultant peptides generally act as potential natural antioxidants against lipid peroxidation and inhibitors of angiotensin Iconverting enzyme (ACE) (Kim et al., 2001; Byun and Kim, 2001). These characteristics suggest that fish gelatin can be used to produce health-functional foods that are not reliant on its physical properties. As extraction temperatures are raised, the yield of gelatin increases, while the physical properties decrease. 
Thus, gelatin extracted under high temperature/high pressure should also be examined to determine whether it can be used for producing functional gelatin hydrolysates with high antioxidative and ACE-inhibiting activities.

Antioxidants are compounds that can interfere with the oxidative cycle, thus inhibiting or slowing the oxidative degradation of polymers. This can be illustrated by considering one of the many mechanisms by which oxidative stress can cause damage, i.e., by stimulating the free-radical chain reaction of lipid peroxidation (Jun et al., 2004). Free-radical chain reactions within a material can be inhibited either by adding chemicals that retard the formation of free radicals or by introducing substances that compete with the existing radicals and remove them from the reaction medium (Jun et al., 2004). Lipid oxidation is of great concern to the food industry and among consumers, as it leads to the development of undesirable off-flavors and potentially toxic reaction products (Maillard et al., 1996). Therefore, antioxidants are increasingly used as a means to enhance the shelf life and improve the stability of lipid and lipid-containing foods. Synthetic antioxidants such as propyl gallate, butylated hydroxyanisole (BHA), and butylated hydroxytoluene (BHT) have been commonly used by the food industry because they are effective and cheap compared with natural antioxidants (Kim et al., 2001a). However, these synthetic antioxidants are suspected of causing some safety risks (Becker, 1993) and have been restricted in their use as food additives. Thus, there is motivation to search for safe and natural antioxidants from various sources. Although several studies have been reported on the isolation of functional peptides from hydro-lysates of fish skin and land animal skin gelatins extracted by conventional methods (Kim et al., 2001a;b ; Qian et al., 2008; Byun and Kim, 2001; Mendis et al., 2005), no research has been conducted that utilizes fish gelatin extracted under high temperature/high pressure as a resource for producing functional gelatin hydrolysates.

The objectives of this study were to obtain functional hydrolysates from rockfish skin gelatin using enzymatic hydrolysis and to characterize the antioxidative activity of the hydrolysates as compared with commercial antioxidants such as ascorbic acid.

\section{Materials and Methods}

\section{Materials}

The rockfish Sebastes hubbsi skin, a by-product of sliced raw fish, was obtained from a fisheries manufacturer of the Geoje National Federation Fisheries Cooperatives (Geoje, Korea) in December 2008. The skin was mechanically separated, and residual muscle and scale were removed manually. After washing thoroughly under running tap water, the skin was placed in polyethylene bags and stored at $-25^{\circ} \mathrm{C}$ until use.

Alcalase (2.4 LFG, from Bacillus licheniformis, optimum temperature and $\mathrm{pH}, 55-70^{\circ} \mathrm{C}$ and $6.5-8.5$, respectively), Flavourzyme (500 MG, from Asperigillus oryzae, optimum temperature and $\mathrm{pH}, 50^{\circ} \mathrm{C}$ and 7.0, respectively), Neutrase $(0.8 \mathrm{~L}$, from Bacillus amyloliiensquefaciens, optimum temperature and $\mathrm{pH}$, $45-55^{\circ} \mathrm{C}$ and 6.0 , respectively), and Protamex (1.5 MG, from Bacillus sp., optimum temperature and $\mathrm{pH}$, $40^{\circ} \mathrm{C}$ and 6.0-7.0, respectively) were purchased from Novo Co. (Novo Nordisk, Bagsvaerd, Denmark).

Soybean oil (Sajo Dongbang Co., Ltd., Seoul, South Korea) for the measurement of antioxidative activity was purchased from a local market in Tongyeong.

All free-radical testing chemicals including 1,1diphenyl-2-picrylhydrazyl (DPPH), 5,5-dimethyl-1pyrroline- $\mathrm{N}$-oxide (DMPO), 2,2-azobis (2-amidinopropane) hydrochloride (AAPH), and $\alpha$-(4-pyridyl-1oxide)- $N$-tert-butylnitrone (4-POBN) were purchased from Sigma-Aldrich Co. (St. Louis, MO, USA).

All of the other reagents used in this study were of analytical grade and were of the highest grade commercially available.

\section{Preparation of the gelatin hydrolysates}

Gelatin from rockfish (Sebastes hubbsi) skin was extracted under high temperature/high pressure according to the method described previously by Kim et al. (2010).

The hydrolysate from rockfish skin gelatin was prepared using a sequential two-step protease treatment. To prepare the first rockfish skin gelatin hydrolysate (FRSGH), the gelatin was added to distilled water at approximately $70^{\circ} \mathrm{C}$ to allow for the gelatin powder to dissolve into solution. A $2 \%(\mathrm{w} / \mathrm{w})$ gelatin was hydrolyzed with one of four enzymes, namely Alcalase, Flavourzyme, Neutrase, or Protamex, at a protein-to-enzyme ratio of 100:2 (w/w) and at optimum enzyme temperatures for 1.0, 1.5, 2.0, 3.0 , and $6.0 \mathrm{~h}$ in a batch reactor. The gelatin was then heated at $98^{\circ} \mathrm{C}$ for $10 \mathrm{~min}$ to inactivate the protease used. The resultant FRSGH was lyophilized and then stored at $-25^{\circ} \mathrm{C}$ until use.

For the preparation of the second rockfish skin gelatin hydrolysate (SRSGH), the FRSGH-A1 
(hydrolyzed with Alcalase) was further hydrolyzed with one of the other three enzymes (Flavourzyme, Neutrase, and Protamex) at a protein-to-enzyme ratio of 100:2 (w/w) and at the enzyme's optimum temperature for $2.0 \mathrm{~h}$. The gelatin was then heated at $98^{\circ} \mathrm{C}$ for $10 \mathrm{~min}$ to inactivate the protease used. The resultant SRSGH was lyophilized and then stored at $-25^{\circ} \mathrm{C}$ until use.

\section{Degree of hydrolysis}

The degree of hydrolysis was evaluated according to the method of Hoyle and Merritt (1994). An equal volume of hydrolysate was mixed with $50 \mathrm{~mL}$ of $20 \%$ trichloroacetic acid (TCA) and centrifuged at $2,560 \times \mathrm{g}$ for $15 \mathrm{~min}$. The resulting supernatant was used for nitrogen analysis and the degree of hydrolysis (DH) was calculated according to the following equations:

$$
\mathrm{DH}(\%)=\frac{10 \% \text { TCA-soluble nitrogen }}{\text { Total nitrogen }} \times 100
$$

\section{Molecular weight profile}

Twenty microliters of the rockfish skin gelatin FRSGH-A1 and SRSGH-F2 were injected onto a Shodex protein $\mathrm{KW}-804$ column (i.d., $8 \mathrm{~mm} \times 300$ $\mathrm{mm}$, Showa Denko, Tokyo, Japan) equilibrated with $50 \mathrm{mM}$ sodium phosphate buffer $(\mathrm{pH}$ 6.0) containing $100 \mathrm{mM} \mathrm{NaCl}$ and analyzed using Shimadzu highperformance liquid chromatography (HPLC) (LC10AT vp, Shimadzu, Kyoto, Japan) at a flow rate of 1 $\mathrm{mL} / \mathrm{min}$. The elution profiles of the rockfish-skin gelatin FRSGH-A2 and SRSGH-F2 were monitored using a Shimadzu UV-vis detector (SPD-10AV vp, Shimadzu) at $280 \mathrm{~nm}$. Molecular weights of the standard proteins (Sigma-Aldrich Chemical Co., St. Louis, MO, USA) used were as follows: aprotinin $(6,500 \mathrm{Da})$, cytochrome c $(12,400 \mathrm{Da})$, carbonic anhydrase (29,000 Da), egg albumin $(45,000 \mathrm{Da})$, bovine serum albumin $(66,000 \mathrm{Da})$, and alcohol dehydrogenase (150,000 Da).

\section{Antioxidative activity}

Antioxidative activity of FRSGH and SRSGH was determined at $120^{\circ} \mathrm{C}$ using an automated Metrohm Rancimat apparatus (Model 743, Herisau, Switzerland) according to the method of Frega et al. (1999). All glasswares were thoroughly cleaned and dried prior to each determination. Soybean oil was weighed directly in the reaction vessels. The hydrolysates $(0.5$ g) were added to $2.5 \mathrm{~g}$ of soybean oil. The air-flow rate through the sample was adjusted to $20 \mathrm{~L} / \mathrm{h}$. The volatile reaction products released during oxidation of the soybean oil were collected in $60 \mathrm{~mL}$ of distilled water in the collection vessel. The change in conductivity was plotted automatically until the end point was reached. With each soybean oil volume, a control test (without hydrolysates) was subjected to the same experimental conditions. The antioxidative activity was measured in duplicate for each sample, and the induction period (IP, h) was recorded. The relative antioxidative activity of the hydrolysates was expressed as the protection factor (PF), which was defined as the ratio of the IP with soybean oil plus hydrolysates to that of the control.

Radical-scavenging activity of SRSGH-F2 was also determined using a JES-FA ESR spectrophotometer (JEOL Ltd., Tokyo, Japan) on DPPH free, hydroxyl, superoxide, and alkyl radical-scavenging activities. DPPH free-radical-scavenging activity was measured using the method described by Nanjo et al. (1996). A $60 \mu \mathrm{L}$ peptide solution (or ethanol as a control) was added to $60 \mu \mathrm{L}$ of DPPH $(60 \mu \mathrm{M})$ in an ethanol solution. After mixing vigorously for $10 \mathrm{sec}$, the solution was transferred into a $100 \mu \mathrm{L}$ quartz capillary tube, and the scavenging activity of the peptide on DPPH free radicals was measured using a JES-FA ESR spectrophotometer (JEOL Ltd., Tokyo, Japan). The spin adduct was measured on an ESR spectrophotometer exactly 2 min later. Experimental conditions were as follows: magnetic field, $336.5 \pm 5$ $\mathrm{mT}$; power, $5 \mathrm{~mW}$; modulation frequency, $9.41 \mathrm{GHz}$; amplitude, $1 \times 1000$; sweep time, 30 sec.

Hydroxyl radical-scavenging activity using ESR spectroscopy was investigated using the method of Rosen and Rauckman (1980). Free radicals produced by the Fenton reaction $\left(\mathrm{Fe}^{2+}+\mathrm{H}_{2} \mathrm{O} \rightarrow \mathrm{OH}+\mathrm{OH}^{-}\right)$, a well-known and -defined generator of $\mathrm{OH}$, were rapidly reacted with the nitron spin trap, DMPO. The reaction mixture contained $20 \mu \mathrm{L}$ sample, $20 \mu \mathrm{L}$ of $0.3 \mathrm{M}$ DMPO, $20 \mu \mathrm{L}$ of $10 \mathrm{mM} \mathrm{FeSO}_{4} \cdot 7 \mathrm{H}_{2} \mathrm{O}$, and 20 $\mu \mathrm{L}$ of $10 \mathrm{mM} \mathrm{H} \mathrm{H}_{2} \mathrm{O}_{2}$. The resultant DMPO-OH adducts were investigated, and the ESR spectra were recorded after $2.5 \mathrm{~min}$. The measurement conditions were as follows: central field, $3,475 \mathrm{G}$; modulation width, $0.2 \mathrm{mT}$; amplitude, $100 \mathrm{mT}$; microwave power, $1 \mathrm{~mW}$; sweep width, $10 \mathrm{mT}$; and temperature, $298 \mathrm{~K}$.

Superoxide radicals were generated by UV irradiation of a riboflavin/EDTA solution, and scavenging was investigated by the method of Zhao et al. (1989). The reaction mixture contained $0.8 \mathrm{mM}$ riboflavin, $1.6 \mathrm{mM}$ EDTA, and $800 \mathrm{mM}$ DMPO, and samples were irradiated for 1 min under a UV lamp at $365 \mathrm{~nm}$. 
The mixtures were transferred into a $100 \mu \mathrm{L}$ quartz capillary tube for measurement using the ESR spectrometer. Experimental conditions were as follows: magnetic field, $336.5 \pm 5 \mathrm{mT}$; power, $10 \mathrm{mV}$; modulation frequency, $9.41 \mathrm{GHz}$; amplitude, $1 \times$ 1,000; sweep time, 1 min.

Alkyl radicals were generated by AAPH, and their scavenging activities were investigated by the method of Hiramoto et al. (1993). The reaction mixture contained $20 \mu \mathrm{L}$ of distilled water, $20 \mu \mathrm{L}$ of extract, $20 \mu \mathrm{L}$ of $40 \mathrm{mM} \mathrm{AAPH}$, and $20 \mu \mathrm{L}$ of $40 \mathrm{mM} \mathrm{4-}$ POBN. The mixture was incubated at $37^{\circ} \mathrm{C}$ for 30 min. The reactants were then transferred to a $50 \mu \mathrm{L}$ glass capillary tube and fitted into the ESR spectrophotometer. The measurement conditions were as follows: central field, 3,475 G; modulation width, 0.2 $\mathrm{mT}$; amplitude, $500 \mathrm{mT}$; microwave power, $8 \mathrm{~mW}$; sweep width, $10 \mathrm{mT}$; and temperature, $298 \mathrm{~K}$.

\section{ACE-inhibiting activity}

ACE-inhibiting activities of FRSGH-A1 and SRSGH-F2 were assayed by measuring the concentration of hippuric acid liberated from hippurylHis-Leu according to the method of Horiuchi et al. (1982), with some modifications. For each assay, 15 $\mu \mathrm{L}$ of sample solution with $50 \mu \mathrm{L}$ of ACE solution (a purified enzyme from rabbit lung) and $100 \mu \mathrm{L}$ of sodium borate buffer $(\mathrm{pH} 8.3)$ were pre-incubated at $37^{\circ} \mathrm{C}$ for $5 \mathrm{~min}$ and then incubated with $125 \mu \mathrm{L}$ of substrate $(5 \mathrm{mM}$ hippuryl-His-Leu in $0.1 \mathrm{M}$ sodium borate buffer containing $0.6 \mathrm{M} \mathrm{NaCl}$ at $\mathrm{pH} 8.3$ ) at $37^{\circ} \mathrm{C}$ for $30 \mathrm{~min}$. The reaction was then stopped by adding $20 \mu \mathrm{L}$ of $10 \%$ trifluoroacetic acid. Hippuric acid concentration was determined using HPLC (Hewlett Packed Co., HP 1100, Palo Alto, California, USA) with a Zorbax $300 \mathrm{SB} \mathrm{C}_{6}$ column $(4.6 \mathrm{~mm} \times 150$ $\mathrm{mm})$. The $\mathrm{IC}_{50}$ value was defined as the concentration of inhibitor required to inhibit $50 \%$ of ACEinhibitory activities.

\section{Amino acid composition}

Amino acid composition of FRSGH-A1- and SRSGH-F2-containing antioxidative peptide was determined using an amino acid analyzer (Biochrom. 30, Pharmacia Biotech., Uppsala, Sweden). The samples were hydrolyzed in concentrated $\mathrm{HCl}$ in evacuated and sealed tubes at $110^{\circ} \mathrm{C}$ for $16 \mathrm{~h}$. The acid-hydrolyzed sample was evaporated and dried in a vacuum evaporator at $40^{\circ} \mathrm{C}$, diluted with sodium citrate buffer ( $\mathrm{pH} 2.2)$, and then used as a sample for amino acids analysis.

\section{Results and Discussion}

\section{Antioxidative activity and other chemical pro- perties of the FRSGH}

The degree of hydrolysis of FRSGH, which was digested with one of four commercial enzymes for 1$6 \mathrm{~h}$, is shown in Fig. 1. The degree of hydrolysis of FRSGH increased within 1.5 (in Protamex and Neutrase systems) to $2.0 \mathrm{~h}$ (in Alcalase and Flavourzyme systems), followed by a slight decrease in all enzyme systems with further hydrolysis. The decrease in the degree of hydrolysis of all FRSGHs incubated for more than $1.5 \mathrm{~h}$ or $2.0 \mathrm{~h}$ may have been caused by inhibition of the enzymes by the resultant hydrolysates or by a reverse reaction such as peptide formation. These results are similar to those reported by Kim et al. (2009). Among the four kinds of hydrolysates digested for $2.0 \mathrm{~h}$, the Alcalase-treated hydrolysate (FRSGH-A2) showed the highest degree of hydrolysis, at $84.5 \%$, followed by the Flavourzyme-treated hydrolysate (FRSGH-F2, 73.0\%), Protamex-treated hydrolysate (FRSGH-P2, 68.7\%), and Neutrase-treated hydrolysate (FRSGH-N2, $61.8 \%)$.

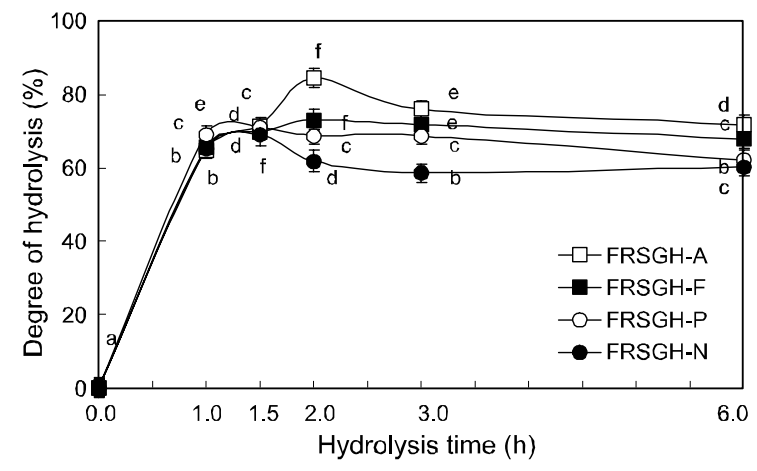

Fig. 1. Degree of hydrolysis of the first rockfish skin gelatin hydrolysates (FRSGH) digested with one of four commercial enzymes at optimum temperature for $1-6 \mathrm{~h}$.

FRSGH-A; gelatin hydrolysate digested with Alcalase at $60^{\circ} \mathrm{C}$, FRSGH-F; gelatin hydrolysate digested with Flavourzyme at $50^{\circ} \mathrm{C}$, FRSGH-P; gelatin hydrolysate digested with Protamex at $50^{\circ} \mathrm{C}$, FRSGH-N; gelatin hydrolysate digested with Neutrase at $40^{\circ} \mathrm{C}$.

Different letters on the symbol indicate a significant difference at $P<0.05$.

The functional properties of bioactive hydrolysates are highly influenced by the molecular structure, molecular mass, and processing conditions. Enzymatic hydrolysis has become the most important tool 
Table 1. Antioxidative activity of the first rockfish skin gelatin hydrolysates (FRSGH) incubated with one of four commercial enzymes at optimum temperature for 1-6 $\mathrm{h}$

\begin{tabular}{lccccc}
\hline & \multicolumn{5}{c}{ Hydrolysis time $(\mathrm{h})$} \\
\cline { 2 - 6 } FRSGH & \multicolumn{7}{c}{ (1) } & 1.0 & 1.5 & 2.0 & 3.0 & 6.0 \\
\hline Control $^{2}$ & $1.00 \pm 0.00$ & $1.00 \pm 0.00$ & $1.00 \pm 0.00$ & $1.00 \pm 0.00$ & $1.00 \pm 0.00$ \\
FRSGH-A & $2.00 \pm 0.05$ & $1.12 \pm 0.09$ & $1.15 \pm 0.07$ & $0.99 \pm 0.05$ & $0.92 \pm 0.10$ \\
FRSGH-F & $1.78 \pm 0.05$ & $1.28 \pm 0.06$ & $1.47 \pm 0.10$ & $1.28 \pm 0.08$ & $1.13 \pm 0.10$ \\
FRSGH-N & $1.27 \pm 0.06$ & $0.94 \pm 0.09$ & $0.99 \pm 0.09$ & $0.91 \pm 0.09$ & $0.97 \pm 0.10$ \\
FRSGH-P & $1.77 \pm 0.04$ & $1.38 \pm 0.06$ & $1.47 \pm 0.06$ & $1.59 \pm 0.08$ & $1.41 \pm 0.02$ \\
\hline
\end{tabular}

${ }^{1)}$ The sample code of FRSGH are the same as shown in Fig. 1.

${ }^{2)}$ The control is defined where no gelatin hydrolysate is added in the antioxidative activity test.

The antioxidative activities of $20 \mathrm{mM}$ ascorbic acid and rockfish skin gelatin were $1.99 \pm 0.03$ and $0.86 \pm 0.07$, respectively.

for modifying the functionality of proteins to identify different bioactivities (Mendis et al., 2005; Korhonen et al., 1998). The antioxidative activity of FRSGH was independent of the type of enzyme used and hydrolysis time (Table 1). Among the forms of FRSGH digested with the same enzyme, the highest antioxidative activity was observed in the FRSGH digested for $1.0 \mathrm{~h}$, which was 2.00 for FRSGH-A1, 1.78 for FRSGH-F1, 1.27 for FRSGH-N1, and 1.77 for FRSGH-P1. Among types of FRSGH, FRSGHA1 showed a superior ACE-inhibiting activity of 1.10 $\mathrm{mg} / \mathrm{mL}\left(\mathrm{IC}_{50}\right.$ value) as well as the highest antioxidative activity of 2.00 (data not shown).

According to our experiments examining the degree of hydrolysis and antioxidative activity of the FRSGH, no correlation between hydrolysis degree and antioxidative activity was found. These results probably indicate that antioxidative activity was only affected by the amino-acid sequence of peptides. Wu et al. (2003) reported no correlation between the degree of hydrolysis and the antioxidative activity of the enzymatic hydrolysates from mackerel. Kim et al. (2001) also reported that the oxidative activity of linoleic acid was inhibited by about $40 \%$ by the addition of hydrolysate from Alaska pollock skin digested with Alcalase.

Amino acid composition (expressed as $\mathrm{g} / 100 \mathrm{~g}$ amino acids) of the FRSGH-A1 (hydrolysate digested with Alcalase for $1 \mathrm{~h}$ ) is shown in Table 2. Amino acid composition of the FRSGH-A1 showed nearly identical values compared with that (Kim et al., 2009) of rockfish-skin collagen. Both were rich in glycine $(25.6 \%)$, proline $(10.9 \%)$, arginine $(10.3 \%)$, alanine $(9.3 \%)$, and glutamic acid $(9.2 \%)$. In contrast, they were poor in cysteine (not detected), methionine $(1.5 \%)$, isoleucine $(0.7 \%)$, tyrosine $(0.4 \%)$, hydroxylysine $(0.9 \%)$, and histidine $(0.9 \%)$. Amino acid compositions were similar to those of other gelatins
Table 2. Amino acid (AA) composition of the FRSGH-A1 ${ }^{1)}$

\begin{tabular}{lclc}
\hline Amino acid & $\mathrm{g} / 100 \mathrm{~g} \mathrm{AA}$ & Amino acid & $\mathrm{g} / 100 \mathrm{~g} \mathrm{AA}$ \\
\hline Aspartic acid & 4.4 & Methionine & 1.5 \\
Hydroxyproline & 8.3 & Isoleucine & 0.7 \\
Threonine & 2.4 & Leucine & 1.8 \\
Serine & 5.3 & Tyrosine & 0.4 \\
Glutamic acid & 9.2 & Phenylalanine & 1.9 \\
Proline & 10.9 & Hydroxylysine & 0.9 \\
Glycine & 25.6 & Lysine & 4.4 \\
Alanine & 9.3 & Histidine & 0.9 \\
Valine & 1.8 & Arginine & 10.3
\end{tabular}

${ }^{1)}$ The FRSGH-A1 was prepared by digesting at $60^{\circ} \mathrm{C}$ for $1 \mathrm{~h}$.

and gelatin hydrolysates from various fish sources (Haug et al., 2004; Jamilah and Harvinder, 2002). Several amino acids such as tyrosine, methionine, histidine, lysine, and tryptophan are commonly accepted as antioxidants (Kim et al., 2001b) despite their pro-oxidative effects in some cases (Marcuse, 1962; Karel et al., 1966; Yamaguchi, 2000).

Results of the FRSGH studies suggest that the Alcalase was the most effective protease for the preparation of hydrolysates, producing a hydrolysate with high antioxidative and ACE-inhibiting activity from rockfish skin gelatin.

\section{Antioxidative activity and other chemical pro- perties of SRSGH}

To prepare SRSGH with various functional properties, FRSGH-A1 was further hydrolyzed with one of the three commercial proteases (Flavourzyme, Neutrase, or Protamex) for 1.0 to $6.0 \mathrm{~h}$.

The degree of hydrolysis increased for SRSGH, excluding SRSGH-N1 and SRSGH-P1, compared with FRSGH-A1 (Fig. 2). The degree of hydrolysis for SRSGH markedly increased within $1.5 \mathrm{~h}$ (SRSGH- 


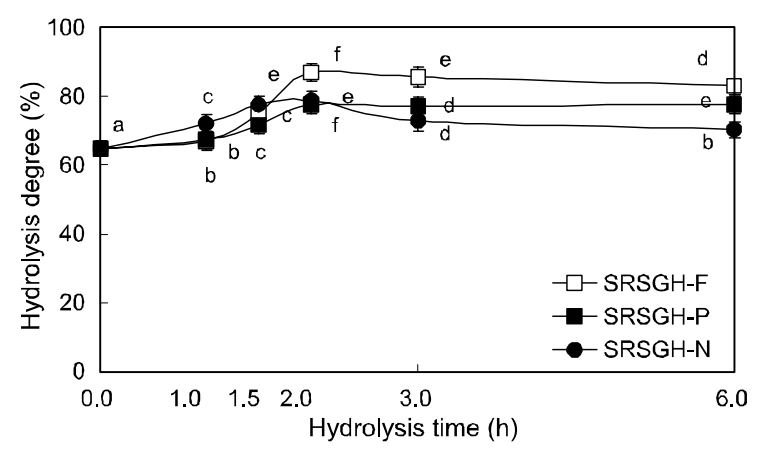

Fig. 2. Hydrolysis degree of the second rockfish skin gelatin hydrolysates (SRSGH) treated with one of three commercial proteases (Flavourzyme, Neutrase and Protamex) for 1.0-6.0 h.

SRSGH-F; SRSGH further hydrolyzed FRSGH-A1 with Flavourzyme for 2 h, SRSGH-P; SRSGH further hydrolyzed FRSGH-A1 with Protamex for $2 \mathrm{~h}$, SRSGH-N; SRSGH further hydrolyzed FRSGH-A1 with Neutrase for $2 \mathrm{~h}$.

Different letters on the symbols indicate a significant difference at $P<0.05$.

$\mathrm{N} 1.5)$ to $2.0 \mathrm{~h}$ (SRSGH-F2 and SRSGH-P2) in all enzyme systems, followed by a slight decrease or little difference with further hydrolysis. The decrease in the degree of hydrolysis was possibly caused by inhibition of enzymes by the products or by a reverse reaction, such as peptide formation. These results are similar to those reported by Chang et al. (2007) and Kim et al. (2009). Among types of SRSGH hydrolyzed for $2.0 \mathrm{~h}$, the degree of hydrolysis was the highest in SRSGH-F2 (66.8\%), followed by SRSGHN2 (78.8\%) and SRSGH-P2 (77.6\%).

Antioxidative activity of SRSGH is shown in Table 3. After further digestion of FRSGH-A1 with one of the three proteolytic enzymes, the antioxidative activity of SRSGH was improved in SRSGH-F2, -N2, -N6, -P1, -P1.5, -P3, and -P6; however, in the other SRSGHs, it was slightly decreased, or little difference

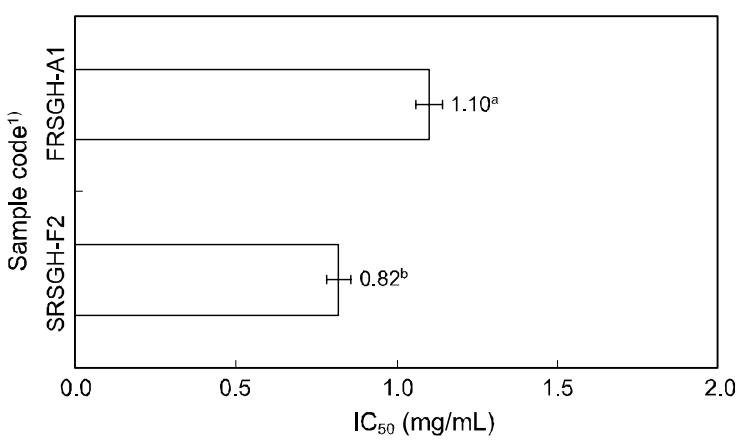

Fig. 3. Angiotensin I converting enzyme $(\mathrm{ACE})^{2)}$ inhibitory activities $\left(\mathrm{IC}_{50}\right)^{3)}$ of FRSGH-A1 and SRSGHF2.

${ }^{1)}$ FRSGH-A1: The first rockfish skin gelatin hydrolysate digested with Alcalase for $1.0 \mathrm{~h}$.

SRSGH-F2: The second rockfish skin gelatin hydrolysate further digested the FRSGH-A1 with Flavourzyme for $2.0 \mathrm{~h}$.

${ }^{2)} \mathrm{ACE}$ inhibition was determined with $15 \mu \mathrm{L}$ of each hydrolysate.

${ }^{3)} \mathrm{IC}_{50}$ value was defined as the concentration of inhibitor required to inhibit $50 \%$ of the ACE inhibitory activity.

${ }^{4)}$ Different letters on the values indicate a significant difference at $P<0.05$.

was observed. These results were probably result from the effect of the amino acid sequence of the peptides on antioxidative activity. Among the SRSGH types described in this experiment, SRSGHF2 showed superior ACE-inhibiting activity at 0.82 $\mathrm{mg} / \mathrm{mL}\left(\mathrm{IC}_{50}\right.$ value; data not shown) as well as the highest antioxidant activity of 3.72. Antioxidative activity of SRSGH-F2 (1.91) was superior to that of $20 \mathrm{mM}$ L-ascorbic acid, which was used as a natural antioxidant.

The ability of SRSGH-F2 to scavenge DPPH free, hydroxy, superoxide, and alkyl radicals was determined by the electron-spin trapping technique. The

Table 3. Antioxidative activities of the second rockfsh skin gelatin hydrolysates (SRSGH) further incubated FRSGH-A1 for 1-6 hrs with one of three kinds of commercial enzymes

\begin{tabular}{lccccc}
\hline & \multicolumn{5}{c}{ Hydrolysis time (hr) } \\
\cline { 2 - 6 } SRSGH $^{1)}$ & 1.0 & 1.5 & 2.0 & 3.0 & 6.0 \\
\hline Control $^{2)}$ & $1.00 \pm 0.00$ & $1.00 \pm 0.00$ & $1.00 \pm 0.00$ & $1.00 \pm 0.00$ & $1.00 \pm 0.00$ \\
SRSGH-F & $2.01 \pm 0.03$ & $1.92 \pm 0.05$ & $3.72 \pm 0.10$ & $1.96 \pm 0.05$ & $1.89 \pm 0.05$ \\
SRSGH-N & $1.42 \pm 0.05$ & $1.59 \pm 0.08$ & $2.18 \pm 0.05$ & $2.08 \pm 0.05$ & $2.12 \pm 0.05$ \\
SRSGH-P & $2.18 \pm 0.05$ & $2.32 \pm 0.06$ & $1.98 \pm 0.06$ & $2.16 \pm 0.06$ & $2.18 \pm 0.05$ \\
\hline
\end{tabular}

Values were given as mean $\pm \mathrm{SD}(\mathrm{n}=3)$.

Sample codes of SRSGH are the same as shown in Fig. 1.

Antioxidative activities of $20 \mathrm{mM}$ ascorbic acid and rockfish skin gelatin were $1.99 \pm 0.03$ and $0.86 \pm 0.07$, respectively. 
resultant chromatograms, expressed as the ESR signal intensity, and radical-scavenging activity (RSA), expressed as a percentage compared with the ESR signal intensity of the control, are shown in Figs. 4 and 5, respectively. Treatment with SRSGH-F2 led to increased scavenging activity upon generation of DPPH radicals by $45.8 \%$ at a concentration of 4 $\mathrm{mg} / \mathrm{mL}$ compared with the control, whereas it was lower than that of $20 \mathrm{mM}$ ascorbic acid $(95.5 \pm 1.0 \%)$. In the presence of the same concentration of SRSGHF2, signals for the superoxide anion-DMPO spin adduct generated in the irradiated riboflavin system were suppressed by $67.8 \%$, and they were lower than that of $20 \mathrm{mM}$ ascorbic acid $(77.4 \pm 0.4 \%)$. A Fenton reaction was utilized to generate hydroxyl radicals, and the typical 1:2:2:1 ESR signal of the DMPO-OH adduct was also suppressed to a higher degree (94.7 \pm $0.1 \%$ ) at the same concentration of SRSGH-F2,

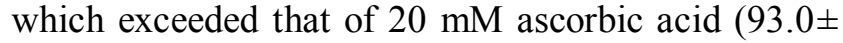
$0.3 \%$ ). These results were probably due to the fact that organic molecules, including peptides, are highly susceptible to oxidation by extremely reactive hydroxyl radicals (Rajapakse et al., 2005). Alkyl radicals were generated from AAPH in the presence of 4-POBN (Kong et al., 2009). As shown in Fig. 4, treatment with SRSGH-F2 significantly reduced the intensity of the spin adduct from the 4-POBN radical generated from AAPH at a concentration of $4 \mathrm{mg} / \mathrm{mL}$ as well as the inhibitory activity (64.8\%) when compared with the control, whereas this effect was not as great as that of $20 \mathrm{mM}$ ascorbic acid $(83.4 \pm$ $1.5 \%)$.

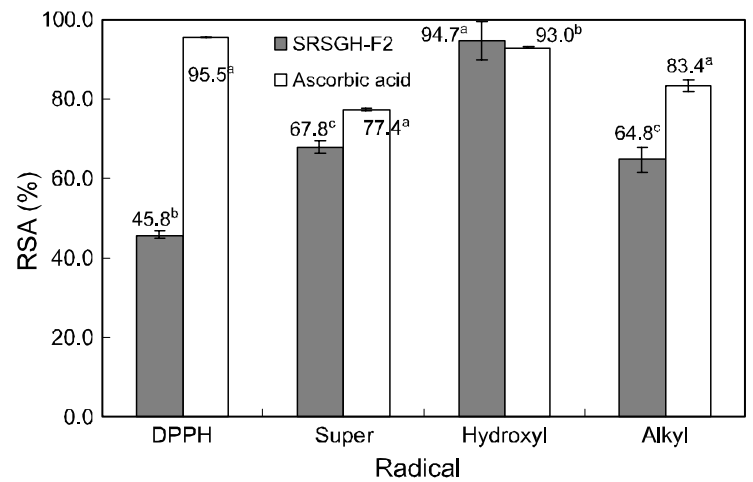

Fig. 4. Radical (DPPH radical, superoxide radical, hydroxyl radical, alkyl radical) scavenging activity (RSA) of SRSGH-F2.

SRSGH-F2: SRSGH further digested the first rockfish skin gelatin with Flavourzyme for $2 \mathrm{~h}$.

Different letters on the values indicate a significant difference at $P<0.05$.
ESR spectrum, analysis of SRSGH-F2 exhibited dose-dependent scavenging effects on all four kinds of radicals; however, the degree of scavenging effects differed. Among the four radicals, hydroxyl radicals were scavenged more effectively.

These results, therefore, indicate that SRSGH-F2 appears to contain some antioxidative peptides. Mendis et al. (2005) reported that antioxidative peptides isolated from hoki skin gelatin hydrolysate are composed of His-Gly-Pro-Leu-Gly-Pro-Leu. Kim et al. (2001) reported that the peptides isolated from gelatin hydrolysate of Alaska pollock skin, P1 and P2, were composed of 13 and 16 amino acid residues, respectively, and both peptides contained glycine residues at the $\mathrm{C}$-terminus and repeating glycineproline-hydroxyproline. In conclusion, sequential enzymatic hydrolysis of rockfish skin gelatin with Alcalase and Flavourzyme enhanced the antioxidative activity of hydrolytic peptides.

The elution profile of the rockfish skin gelatins, FRSGH-A1 and SRSGH-F2, were analyzed using gel chromatography on a Sephadex G-50, and the results are shown in Fig. 6. The rockfish skin gelatin was characterized by relatively low proportions of the $100 \mathrm{kDa}$ peak, estimated as an $\alpha$ fraction, and relatively high proportions of the $6.5 \mathrm{kDa}$ peak. The peptide chain length, which depends on the degree of

Table 4. Amino acid (AA) composition of the first (FRSGH-A1) and the second rockfish skin gelatin hydrolysates (SRSGH-F2) $(\mathrm{g} / 100 \mathrm{~g} \mathrm{AA})$

\begin{tabular}{lcc}
\hline \multirow{2}{*}{ Amino acid } & \multicolumn{2}{c}{ Rockfish skin gelatin hydrolysates ${ }^{1)}$} \\
\cline { 2 - 3 } & FRSGH-A1 & SRSGH-F2 \\
\hline Aspartic acid & 4.4 & 4.3 \\
Hydroxyproline & 8.3 & 8.8 \\
Threonine & 2.4 & 2.5 \\
Serine & 5.3 & 5.2 \\
Glutamic acid & 9.2 & 9.1 \\
Proline & 10.9 & 10.8 \\
Glycine & 25.6 & 25.9 \\
Alanine & 9.3 & 9.1 \\
Valine & 1.8 & 2.1 \\
Methionine & 1.5 & 1.6 \\
Isoleucine & 0.7 & 0.8 \\
Leucine & 1.8 & 1.9 \\
Tyrosine & 0.4 & 0.4 \\
Phenylalanine & 1.9 & 2.0 \\
Hydroxylysine & 0.9 & 0.9 \\
Lysine & 4.4 & 4.5 \\
Histidine & 0.9 & 0.9 \\
Arginine & 10.3 & 9.2 \\
\hline Total & 100.0 & 100.0 \\
\hline
\end{tabular}

${ }^{1)}$ FRSGH-A1: FRSGH hydrolyzed rockfish skin gelatin with Alcalase at $60^{\circ} \mathrm{C}$ for $1.0 \mathrm{~h}$, SRSGH-F2: SRSGH hydrolyzed FRSGH-A1 with Flavourzyme for $2.0 \mathrm{~h}$. 


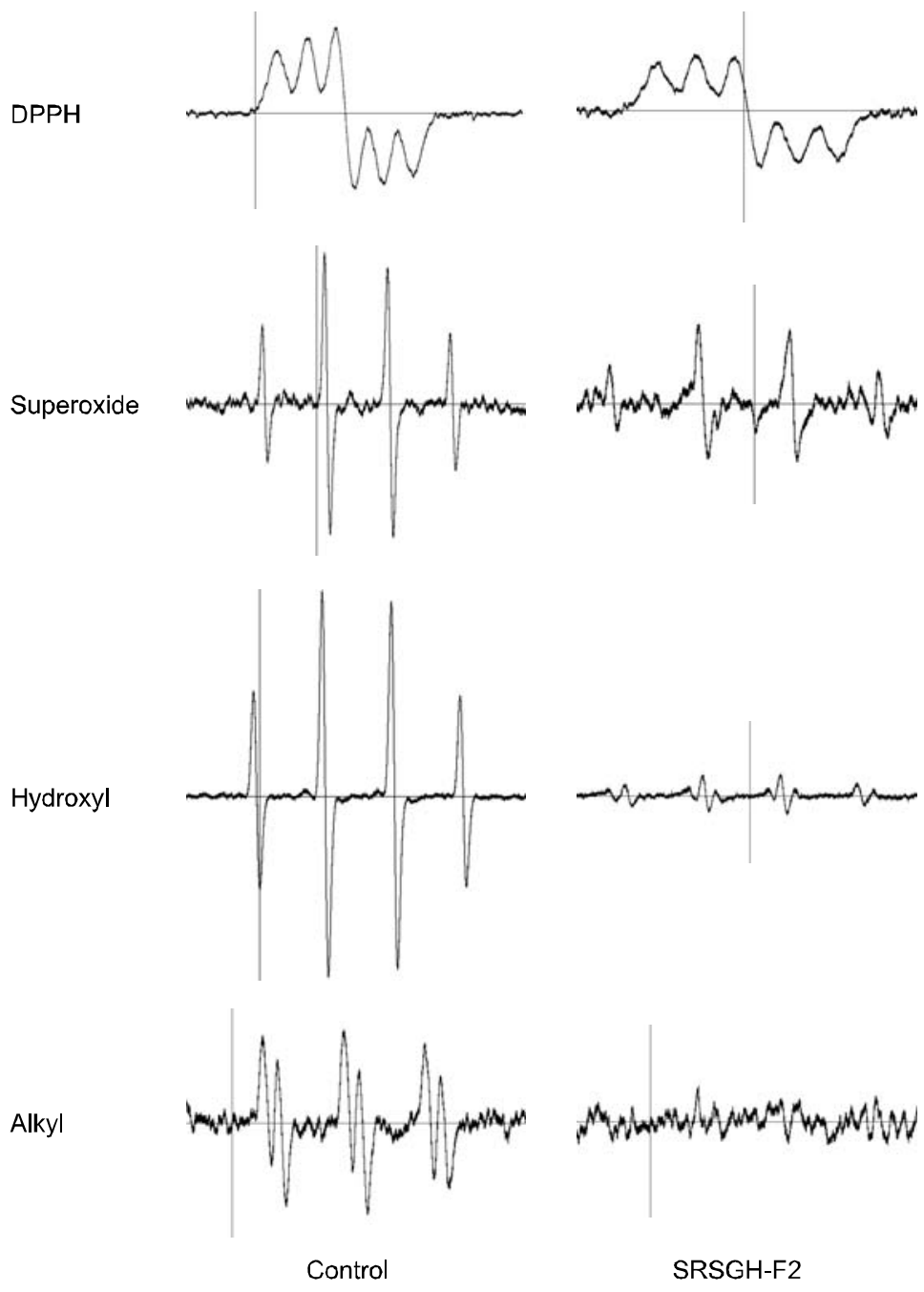

Fig. 5. Radical (superoxide radical, hydroxyl radical, DPPH radical) scavenging chromatograms of SRSGH-F2. SRSGH-F2: the second rockfish skin gelatin hydrolysate re-hydrolyzed FRSGH-A1 with Flavourzyme for $2 \mathrm{~h}$.

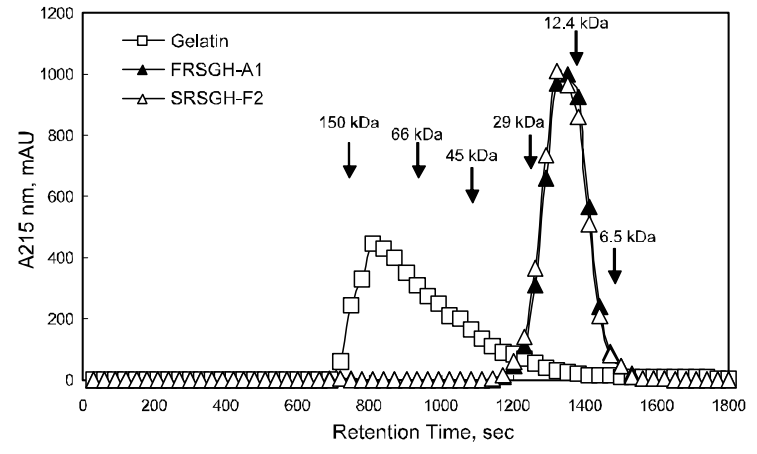

Fig. 6. Molecular weight distribution profiles of rockfish skin gelatin under high temperature/high pressure, FRSGH-A1 and SRSGH-F2.

${ }^{1)}$ FRSGH-A1: The first rockfish skin gelatin hydrolysate digested with Alcalase for $1.0 \mathrm{~h}$, SRSGH-F2: The second rockfish skin gelatin hydrolysate further digested FRSGH-A1 with Flavourzyme for $2.0 \mathrm{~h}$. hydrolysis, is of special interest with respect to organoleptic and health-functional characteristics (Gbogouri et al., 2004). When compared with the gelatin, the relative proportion in both FRSGH-A1 and SRSGH-F2 markedly decreased in the $100 \mathrm{kDa}$ peak, whereas it increased in that less than $100 \mathrm{kDa}$. The pattern was distinct, as the enzymatic hydrolysis was sequentially advanced. Jeon et al. (1999) reported a correlation between the molecular weight of a hydrolysate and the specificity of the antioxidation activity. According to the molecular weight profiles and the reports by Jeon et al. (1999), SRSGH-F2 is expected to show high antioxidative activity compared with other gelatin-related materials such as rockfish skin gelatin and FRSGH.

Amino acid composition of FRSGH-A1 and SRSGH-F2 is shown in Table 4. The amino acid 
composition of SRSGH-F2 was rich in glycine $(25.9 \%)$, proline $(10.8 \%)$, alanine $(9.1 \%)$, and glutamic acid $(9.1 \%)$. In contrast, it was poor in cystine (not detected), methionine $(1.6 \%)$, tyrosine $(0.4 \%)$, hydroxylysine $(0.9 \%)$, and histidine $(0.9 \%)$. The amino acid composition of SRSGH-F2 showed nearly identical values as compared with FRSGH-A1.

These results suggest that SRSGH-F2 could be used as a supplementary raw material for improving health-functional properties, such as antioxidative and ACE-inhibiting activities.

\section{Acknowledgments}

This work was supported by Korea Research Foundation Grant funded by the Korean Government (KRF-2008-521-F00044).

\section{References}

Becker GL. 1993. Preserving food and health: antioxidants make fuctional, nutritious preservatives. Food Process 4, 885-889.

Byun HG and Kim SK. 2001. Purification and characterization of angiotensin I converting enzyme (ACE) inhibitory peptides from Alaska pollock (Theragra chalcogramma) skin. Process Biochemistry 36, 11551162.

Chang CY, Wu KC and Chiang SH. 2007. Antioxidant properties and protein compositions of porcine haemoglobin hydrolysates. J Food Chem 100, 15371543.

Fishery Production Survey. 2010. http://fs.fips.go.kr

Frega N, Mozzon M and Lecker G. 1999. Effects of free fatty acids on oxidative stability of vegetable oil. J Agric Food Chem 47, 1035-1040.

Gbogouri GA, Linder M, Fanni J and Parmentier M. 2004. Influence of hydrolysis degree on the functional properties of salmon byproducts hydrolysates. J Food Sci 69, C615-C622.

Haug IJ, Draget KI and Smidsrod O. 2004. Physical and rheological properties of fish gelatin compared to mammalian gelatin. Food Hydrocolloids 18, 203-213.

Hiramoto K, Jonkoh H, Sako KI and Kikugawa K. 1993. DNA breaking activity of the carbon-centered radical generated from 2,2'-azobis (2 amidinopropane) hydrochloride (AAPH). Free Radic Res Commun 19, 323332.

Horiuchi M, Fujimura KI, Terashima T and Iso T. 1982. Method for determination of angiotensin I converting enzyme activity in blood and tissue by high-performance liquid chromatography. J Chromatogr 233,
123-130.

Hoyle N and Merritt JH. 1994. Quality of fish protein hydrolysates from herring (Clupea harengus). J Food Sci 59, 76-79, 129.

Jamilah B and Harvinder KG. 2002. Properties of gelatins from skins of fish-black tilapia (Oreochromis mossambicus) and red tilapia (Oreochromis nilotica). Food Chem 77, 81-84.

Jeon YJ, Byun HG and Kim SK. 1999. Improvement of functional properties of cod frame protein hydrolysates using ultrafiltration membranes. Process Biochem 35, 471-478.

Jun SY, Park PJ, Jung WK and Kim SK. 2004. Purification and characterization of an antioxidative peptide from enzymatic hydrolysate of yellowfin sole (Limanda aspera) frame protein. J Eur Food Res and Tech 219, 20-26.

Karel M, Tannenbaum SR, Wallace DH and Maloney H. 1966. Autooxidation of methyl linoleate in freeze dried model systems. Effects of added amino acids. J Food Sci 31, 892-896.

Kim HJ, Jee SJ, Yoon MS, Youn MH, Kang KT, Lee DH, Heu MS and Kim JS. 2009. Characterization of acidand pepsin-soluble collagens from rockfish Sebastes schlegeli skin. J Fish Sci Tech 12, 6-15.

Kim HJ, Yoon MS, Park KH, Shin JH, Heu MS and Kim JS. 2010. Processing optimization of gelatin from rockfish skin based on yield. Fish Aqua Sci 13, 1-11.

Kim JS and Park JW. 2004. Characterization of acidsoluble collagen from Pacific whiting surimi processing byproducts. J Food Sci 69, C637-C642.

Kim SK, Byun HG, Jeon YJ and Cho DJ. 1994. Functional properties of fish skin gelatin hydrolysate from a continuous two-stage membrane reactor. Korean Agric Chem Biotechnol 37, 85-93.

Kim SK, Byun HG, Park PJ and Shahidi F. 2001a. Angiotensin I converting enzyme inhibitory peptides purified from bovine skin gelatin hydrolysate. J Agric Food Chem 49, 2992-2997.

Kim SK, Kim YT, Byun HG, Nam KS, Joo DS and Shahidi F. 2001b. Isolation and characterization of antioxidative peptides from gealtin hydrolysate of Alaska pollack skin. J Agric Food Chem 49, 19841989.

Kong CS, Kim JA, Qjan ZJ, Kim YA, Lee JI, Kim SK, Nam TJ and Seo Y. 2009. Protective effect of isorhamnetin 3-O- $\beta$-D-glucopyranoside from Salicornia herbacea against oxidation-ionduced cell damage. Food Chem Toxicol 47, 1914-1920.

Korhonen H, Pihlanto-Leppala A and Tupasela T. 1998. Impact of processing on bioactive proteins and peptides. Trends Food Sci Technol 9, 307-319.

Maillard MG, Soum MH, Meydani SN and Berset C. 1996. 
Antioxidant activity of barely and malt: relationship with phenolic content. Food Sci Tech 29, 238-244.

Marcuse R. 1962. The effect of some amino acids on the oxidation of linoleic acid and its methyl ester. J Am Oil Chem Soc 39, 97-103.

Mendis E, Rajapakse N and Kim SK. 2005. Antioxidant properties of a radical-scavenging peptide purified from enzymatically prepared fish skin gelatin hydrolysate. J Agric Food Chem 53, 581-587.

Nanjo F, Goto K, Seto R, Suzuki M, Sakai M and Hara Y. 1996. Scavenging effects of tea catechins and their derivatives on 1,1-diphenyl-2-picrylhydrazyl radical. Free Radic Biol Med 21, 895-902.

Qian ZJ, Jung WK and Kim SK. 2008. Free radical scavenging activity of a novel antioxidative peptide purified from hydrolysate of bullfrog skin, Rana catesbeiana Shaw. Biores Tech 99, 1690-1698.

Rajapakse N, Mendis E, Jung WK, Je JY and Kim SK. 2005. Purification of a radical scavenging peptide from fermented mussel sauce and its antioxidant properties. Food Research International 38, 175-182.

Rosen GM and Rauckman EJ. 1980. Spin trapping of superoxide and hydroxyl radicals. Method Enzymol 105, 198-209.

Wu HC, Chen HM and Shiau CY. 2003. Free amino acids and peptides as related to antioxidant properties in protein hydrolysates of mackerel (Scomber Austriasicus). Food Research International 36, 949-957.

Yamaguchi F, Ariga T, Yoshimira Y and Nakazawa H. 2000. Antioxidant and antiglycation of carcinol from Garcinia indica fruit rind. J Agric Food Chem 48, 180-185.

Zhao BL, Li XJ, He R, Cheng SJ and Xin WJ. 1989. Scavenging effect of extracts of green tea and natural antioxidants on active oxygen radicals. Cell Biophys $14,175-185$.

(Received 29 December 2010; Revised 28 February 2011; Accepted 9 March 2011) 